\title{
Pankreas kanseri -karaciğer metastazlarında difüzyon ağırlıklı manyetik rezonans görüntüleme
}

\author{
Diffusion weighted magnetic resonance imaging of hepatic metastasis of pancreatic cancer
}

\author{
Melike Ruşen METIN', Mustafa TAHTACl² \\ Sağlık Bakanlığı Atatürk Eğitim ve Araştırma Hastanesi, ${ }^{1}$ Radyoloji Bölümü, Ankara \\ Yıldırım Beyazıt Üniversitesi Tıp Fakültesi, 'ªastroenteroloji Bilim Dalı, Ankara
}

Giriş ve Amaç: Pankreas kanseri günümüzde sık görülen, medikal tedaviye dirençli ve kötü prognozlu tümörlerden biridir. Görüntüleme yöntemleri ile hem primer tümörün hem de metastazlarının saptanmasında güçlükler yaşanmaktadır. Bu çalışmanın amacı pankreas kanserinde operabilite kriterlerinden olan karaciğer metastazlarının saptanmasında çok kesitli bilgisayarlı tomografi ve difüzyon ağırlıklı görüntüleme sekansları ile birlikte manyetik rezonans görüntülemenin katkılarını karşılaştırmaktır. Gereç ve Yöntem: 2012-2017 yılları arasında merkezimizde pankreas kanseri tanısı alan 79 hastaya ait çok kesitli bilgisayarlı tomografi ve difüzyon ağırlıklı manyetik rezonans görüntüleri retrospektif olarak değerlendirildi. Çalışmaya dahil ettiğimiz 63 hastanın 45'i adenokanser, 18'i pankreatik nöroendokrin tümör tanısı alan hasta idi. Çok kesitli bilgisayarlı tomografi ve difüzyon ağırlıkı manyetik rezonans görüntülemede tespit edilen karaciğer metastazları sayı olarak karşılaştıııldı. Ayrıca manyetik rezonans görüntüleme ile her iki grup primer tümörlerinden yapılan görünür difüzyon katsayısı ölçümleri arasında anlamlı fark olup olmadığı ve her iki gruba ait metastatik kitleler arasındaki görünür difüzyon katsayı değerlerinin farkı incelendi. Bulgular: Difüzyon ağırlıklı manyetik rezonans görüntülemede çok kesitli bilgisayarlı tomografiye kıyasla daha fazla sayıda metastaz tespit edildi $(\% 38,10)$. Adenokanser ve pankreatik nöroendokrin tümörlerde primer tümörlerden yapılan ölçümlerde görünür difüzyon katsayı değerleri dağılımları istatistiksel olarak önemli bir farklılık göstermedi ( $p=0.976$ ). Aynı şekilde her iki gruba ait metastazlardan yapılan görünür difüzyon katsayı ölçümlerinde istatistiksel olarak anlamlı fark saptanmadı ( $p=0.140$ ). Tartışma: Pankreas kanseri hastalarında tek tedavi yönteminin cerrahi olduğu düşünüldüğünde evreleme ve tümör tipinin belirlenebilmesi açısından hem primer kitlelerin hem de metastazlarının görüntüleme yöntemleriyle tanısının ne kadar önemli olduğu anlaşılmaktadır. Günümüzde henüz pankreas kanseri hastalarında karaciğer metastazlarının tespit ve spesifiye edilmesinde kullanılan uluslararası bir kılavuz yayınlanmamıştır. Ancak kontrastlı çok kesitli bilgisayarlı tomografi incelemelerinde tespit edilen fakat spesifiye edilemeyen karaciğer kitlelerinde manyetik rezonans görüntülemeye başvurulmaktadır. Konvansiyonel manyetik rezonans görüntüleme incelemelerinde de benzer sıkıntılar yaşanabilmektedir. Difüzyon ağırlıklı manyetik rezonans görüntüleme ile inceleme konvansiyonel manyetik rezonans görüntüleme sekanslarına ek sekans olarak aynı oturumda ve kısa sürede yapılabilmektedir. Bu çalışmada pankreas kanseri tanılı hasta serimizde hastaların \%38,10'nunda; difüzyon ağırlıklı manyetik rezonans görüntüleme ile incelemede çok kesitli bilgisayarlı tomografiden daha fazla karaciğer metastazı saptandı. Bu nedenle gereksiz cerrahi ve cerrahinin neden olduğu morbidite ve mortaliteden korunmak amacılla pankreas kanseri tanılı hastalarda karaciğer metastazı saptanması ve dolayısıyla evrelemede difüzyon ağırlıklı manyetik rezonans görüntülemenin tarama amaçlı gerçekleştirilmesi gerektiğini düşünmekteyiz.

Anahtar kelimeler: Pankreatik kanser, difüzyon ağırlıkı manyetik rezonans, çok kesitli bilgisayarlı tomografi, karaciğer metastazı
Background and Aims: Pancreatic cancer is one of the tumors that occurs most commonly, is resistant to medical treatment, and has a poor prog nosis. Imaging methods present difficulties in detecting both primary and metastatic tumors. The aim of this study was to compare the contribution of diffusion-weighted magnetic resonance imaging with that of multiple detector computed tomography in the detection of liver metastases based on the operability criteria of pancreatic cancer.Materials and Methods: Multiple detector computed tomography and diffusion-weighted magnetic resonance imaging images of 79 patients diagnosed with pancreatic cancer in our center during 2012-2017 were evaluated retrospectively. Of the 63 patients included in the study, 45 had adenocarcinoma and 18 had pancreatic neuroendocrine tumor. The liver metastases detected via multiple detector computed tomography and diffusion-weighted magnetic resonance imag ing images were compared. The liver metastases detected in multiple detector computed tomography and diffusion-weighted magnetic resonance imaging were compared in numbers. In addition, the difference between the apparent diffusion coefficient measurements between the two groups of primer tumors in magnetic resonance imaging and the difference between the apparent diffusion coefficient values between the metastatic masses in both groups were examined. Results: A larger number of metastases were detected in diffusion-weighted magnetic resonance imaging than in multiple detector computed tomography images (38.10\%). The distributions of apparent diffusion coefficient values of the measurements made from primary tumors in patients with adenocarcinoma and pancreatic neuroendocrine tumor were not statistically significant $(p=0.976)$. Similarly, there was no statistically significant difference between the apparent diffusion coefficient measurements obtained from the metastases of both groups $(p=0.140)$. Discussion: When we consider the fact that the only treatment method for pancreatic cancers is surgery, it is understood how important it is to recognize both primary masses and metastases using imaging methods to determine the staging and tumor type. Currently, there are no published international guidelines for the identification and specification of liver metastases in patients with pancreatic cancer. However, magnetic resonance imaging has been applied to detect liver masses in contrast-enhanced multiple detector computed tomography, though not specifically. Similar problems can be experienced in conventional magnetic resonance examinations. Diffusion-weighted magnetic resonance imaging examination can be performed in the same session and in a short time as an additional sequence to conventional magnetic resonance sequences. In this study, more metastases were detected in diffusion-weighted magnetic resonance imaging than multiple detector computed tomography in \%38,10 of the patients diagnosed with pancreas cancer. To prevent morbidity and mortality caused due to unnecessary surgeries, we believe that liver metastasis should be detected in patients with pancreatic cancer, and therefore, diffusion-weighted magnetic resonance imaging should be performed for screening purposes.

Key words: Pancreatic cancer, diffusion weighted magnetic resonance im aging, multiple detector computed tomography, hepatic metastasis

\footnotetext{
Illetişim: Melike Ruşen METiN

Sağlık Bakanlığı Atatürk Eğitim ve Araştırma Hastanesi,

Radyoloji Bölümü, Ankara

E-mail: melikemetinrusen@gmail.com
}

Geliş Tarihi: 29.03.2018 • Kabul Tarihi: 17.08.2018 


\section{GíRiş}

Pankreas kanseri günümüzde en sık görülen, tedaviye dirençli ve kötü prognozlu tümörlerden biridir. Genellikle erken evrede klinik bulgu vermemesi sebebiyle geç tanı alır ve riskli hastalarda bile erken tanıyı sağlayan bir tarama testi henüz saptanmamıştır (1). Hipovasküler ve hipoksik olan pankreas kitlelerinde konvansiyonel kemoterapi yöntemleri etkisiz kalmaktadır. 5 yıllık survi $\% 5^{\prime}$ den azdır ve ancak \%10-20'si opere olabilmektedir $(2,3)$ Pankreas kanserinde risk faktörleri arasında kronik pankreatit, diyabet, herediter pankreatit, aile hikayesi, sigara içimi bulunmaktadır. Son ylllarda BRCA1, BRCA2, PALB2, p16 gibi gen mutasyonları da risk faktörleri arasında sayılmaktadır $(4,5)$. Serum kanseri antijeni 19-9 da düşük özgünlüğe sahiptir ve daha sıklıkla hastalığın ilerlemesini belirtmek için kullanııı (6).

Görüntüleme yöntemleri ile hem primer tümörün hem de metastazlarının saptanmasında hala güçlükler yaşanmaktadır. Oysa gereksiz operasyonların önlenmesi açısından evrelemenin optimal şekilde yapılması gerekmektedir. Pankreas kanseri tanısında kullanılan görüntüleme yöntemleri ultrasonografi (USG), çok kesitli bilgisayarlı tomografi (ÇKBT), manyetik rezonans görüntüleme (MRG), endoskopik ultrasonografi (EUS) ve florin-18-2-floro-2deoksi-D-glikoz (FDG) pozitron emisyon tomografi (PET/ BT)'dir (4).

Bu çalışmanın amacı; pankreas kanserinde operabilite kriterlerinden olan karaciğer metastazlarının saptanmasında ÇKBT ve difüzyon ağırlıklı görüntüleme (DAG) sekansları ile birlikte MRG'nin katkılarını karşısş̧ırmaktı. Ayrıca adenokanser ile pankreatik nöroendokrin tümör (Pan-NET) tanısı alan hastalarda her iki gruba ait primer kitle ve metastazları arasında DAG MRG bulguları açısından karşılaştırma yapıldı. Bunun için retrospektif olarak hastaların ÇKBT ve DAG MRG bulguları ile laparotomi, laparoskopi, operasyon, biyopsi ve takip bulguları ile korelasyonu araştıııldı.

\section{GEREÇ ve YÖNTEM}

2012-2017 yılları arasında merkezimizde patoloji sonuçlarına göre adenokanser ve PanNET tanısı alan 79 pankreas kitlesi yeniden değerlendirildi. Araştırmaya hem ÇKBT hem de DAG MRG inceleme yapılan hastalar dahil edildi. Yalnız ÇKBT ile tanı ve tedavi alan 12 hasta ve patoloji sonucuna ulaşamadığımız 4 hasta çalışmadan çıkarıldı. ÇaIışmaya dahil ettiğimiz 63 hastanın 45'i adenokanser, 18'i PanNET tanısı alan hasta idi. Dünya Sağlık Örgütü (WHO) sınıflandırması 2010'a göre PanNET'lerin 5'i grade 1, 8'i grade $2,5^{\prime} i$ grade 3 tümör idi.
Tüm görüntüler abdominal görüntülemede 13 yıllık deneyimi olan radyoloji uzmanı tarafından değerlendirildi.

ÇKBT incelemeleri, 256 kesitli, Siemens SOMATOM Multislice BT'de gerçekleştirildi. Abdominal BT tetkik parametreleri; $124 \mathrm{~mm}$ FOV, 0,60 mm kolimasyon, 0,35, 120-150 kvP/150-200 mAs, aksiyal, koronal ve sagital 3D rekonstrüksiyonlar altında 1 mm kesit kalınlığı, tarama süresi yaklaşık 12,4 sn idi.

MRG incelemelerinde 48 kanallı 3T MR (MAGNETOM Skyra Siemens) kullanıldı. Difüzyon ağırlıkı görüntüleme, yağ baskılı ve nefes tutmalı bir spin-eko, eko-düzlemsel görüntüleme dizisi kullanarak transvers düzlemde gerçekleştirildi. Parametreler; 12.000/100/2.200 msn tekrar/eko inversiyon zamanı, 3 dikey doğrultuda difüzyon gradyan kodlaması; eğim genlik (b-değeri): 0-800 sn/ mm2, görüş alanı 400 mm, matris boyutu 134-108 piksel, kesit kalınlık 6 mm, kesit aralığı 3 mm ve elde edilen sinyaller sayısı 1 idi. DAG taramaları, kontrastı T1 ağırlıklı görüntülemeden önce elde edildi.

DAG sekanslarda ortalama görünür difüzyon katsayısı (ADC) ölçümleri yapılırken literatürle uyumlu olarak ilgilenilen alan (ROI) çapı mümkün olduğu kadar küçük tutmaya çalışıldı (ortalama ROI çapı 20 mm) ve her hastada aynı ROI çapı kullanıldı (7). Nekroz, hemoraji ya da kalsifikasyon ihtiva eden kitlelerde ölçümler kitlenin en homojen ve solid kısmından yapıldı (Resim 1 A, B).

MRG incelemede DAG'in yanlış pozitif sonuçlarından etkilenmemek için diğer MRG sekansları ile birlikte değerlendirme yapıldı. Adenokanser ve PanNET'lerde primer tümörlerden ve metastazlarından yapılan ölçümlerde bu iki grup tümör arasında ADC değerleri arasında anlamlı fark olup olmadığı araştııııdı.

\section{İstatiksel Analiz}

Verilerin istatistik değerlendirmeleri SPSS (Statistical Package for the Social Sciences) 15.0 versiyonu istatistik paket programı ile yapıldı. Sürekli değişkene ait veriler ortalama \pm standart sapma, medyan ile aralık ve kategorik değişkenlere ait veriler frekans ile yüzde olarak belirtildi. Korelasyonlar için Pearson korelasyon testi, grupların karşılaştıııldığı analizlerde kategorik değişkenler için Ki-Kare test ile Fisher exact test ve sürekli değişkenler için Mann Whitney $U$ test uygulandı. Sonuçlar \%95 güven aralığında, anlamlılık $p<0.05$ düzeyinde kabul edilerek değerlendirildi $\left({ }^{*} p<0.05{ }^{* *} p<0.01{ }^{* * *} p<0.001\right)$. 

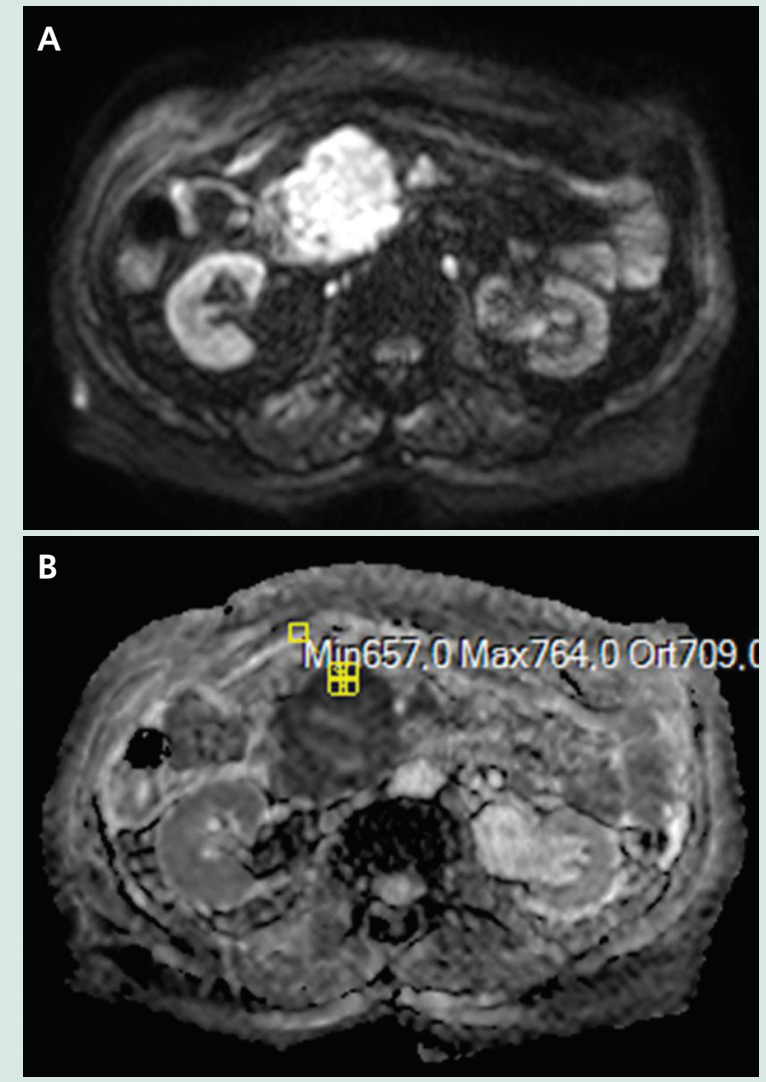

Resim 1 A,B. DAG MRG'da primer kitle hiperintens görünümde$\operatorname{dir}(\mathbf{A})$. ADC haritalamada hipointens görünümdeki kitleden $\mathrm{ROI}$ ile yapılan $A D C$ ölçümü (B).

\section{BULGULAR}

Altmış üç hastanın 40'ı $(\% 63,5)$ erkek, 23'ü $(\% 36,5)$ kadındı (erkek/kadın: 1,7) PanNET ve adenokanser hastalarında iki grup arasında cinsiyet dağılımında istatistiksel olarak önemli bir farklılık saptanmadı (Tablo 1). Pankreas

Tablo 1. Grupların cinsiyet bilgileri $p=0.363$ (gruplar arasında cinsiyet dağılımı istatistiksel olarak önemli bir farklılık göstermemektedir).

\begin{tabular}{|ccccc|} 
& \multicolumn{2}{c}{ PanNET } & \multicolumn{2}{c|}{ Adenokanser } \\
\hline & $\mathbf{n}$ & $\%$ & $\mathbf{n}$ & $\%$ \\
\hline Kadın & 5 & 27,80 & 18 & 40,00 \\
\hline Erkek & 13 & 72,20 & 27 & 60,00 \\
\hline
\end{tabular}

kanserinin ortalama görülme yaşı 60,32 idi. Bu iki grup arasında yaş dağılımı istatistiksel olarak önemli bir farklılık göstermekte idi. Buna göre; adenokanser grubundaki hastalar PanNET grubuna kıyasla daha yaşlı idi $(p=0.040)$ (Tablo 2).

Kitle lokalizasyonları; 18 hastada kuyruk, 36 hastada pankreas başı, 6 hastada gövde, 3 hastada unsinat prosesdeydi (Resim 2). 18 NET kitlesinin 9'u kuyruk lokalizasyonunda, 3'ü gövdede, 6'sı pankreas başında idi (Resim 3). 45 adenokanser kitlesinin 9'u kuyruk, 3 tanesi gövde, 3 tanesi uncinat prosess, 30'u baş lokalizasyonunda idi. Bu has-

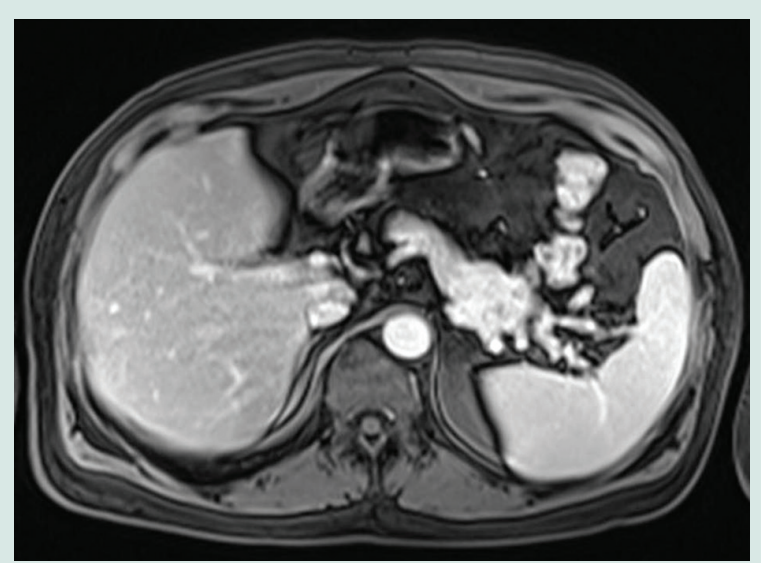

Resim 2. Kontrastlı T1A sekansta pankreas kuyruğunda izlenen primer kitle (adenokanser).

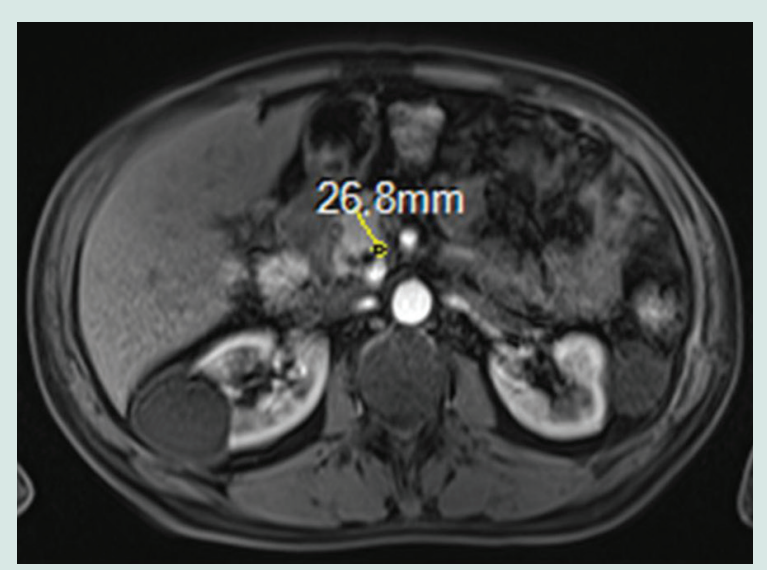

Resim 3. Kontrastlı T1A sekansta pankreas başında izlenen primer kitle (PanNet).

Tablo 2. Grupların yaş istatistik bilgileri; adenokanser grubundaki hastalar PanNET grubuna kıyasla daha yaşlıdır $(p=0.040)$.

\begin{tabular}{|lcccccc|} 
Grup & $\mathbf{n}$ & Ortalama & Standart Sapma & Medyan & Minimum & Maksimum \\
\hline PanNET & 18 & 53,67 & 16,26 & 55,50 & 4,00 & 77,00 \\
\hline Adenokanser & 45 & 62,98 & 12,55 & 63,00 & 40,00 & 84,00 \\
\hline
\end{tabular}

PanNET: Pankreatik nöroendokrin tümör. 
talardan 8'ine distal pankreatektomi, 17 hastaya Whiple operasyonu, 6 hastaya enükleasyon operasyonu yapıldı. Metastatik olması nedeniyle 25 hasta inoperabl kabul edildi. 1 hasta multipl karaciğer metastazları olmasına rağ-

\begin{tabular}{|c|c|c|c|c|}
\hline & \multicolumn{2}{|c|}{ PanNET } & \multicolumn{2}{|c|}{ Adenokanser } \\
\hline & $n$ & $\%$ & $n$ & $\%$ \\
\hline İzointens & 0 & 0.00 & 5 & 11.10 \\
\hline Hipointens & 14 & 77.80 & 33 & 73.30 \\
\hline Hiperintens & 4 & 22.20 & 7 & 15.60 \\
\hline
\end{tabular}

Tablo 4. Gruplar arasında T2 sekansında Sı ölçümlerine ait istatistikler.

\begin{tabular}{lcccc} 
& \multicolumn{2}{c}{ PanNET } & \multicolumn{2}{c|}{ Adenokanser } \\
& $\mathbf{n}$ & $\%$ & $\mathbf{n}$ & $\%$ \\
\hline İointens & 0 & 0.00 & 5 & 11.10 \\
\hline Hipointens & 7 & 38.90 & 12 & 26.70 \\
\hline Hiperintens & 11 & 61.10 & 28 & 62.20 \\
\hline
\end{tabular}

men hormon aktif insulinoma olması nedeniyle primer tümör yükünü azaltma amacıyla opere (Whiple operasyonu) edildi. Diğer 6 hastanın patolojik tanısı tru-cut biyopsi ya da ince iğne aspirasyon biyopsisi (IIAB) ile kondu.

PanNET'ler ve adenokanserlerde T1 ve T2 ağırlıklı sekanslardaki sinyal özellikleri değerlendirildi (Tablo 3 ve Tablo 4). T1A sekanslarda; PanNET'lerin \%77,7'si, adenokanserlerin $\% 73,3^{\prime}$ ü hipointens, PanNET'lerin \%22,2'si, adenokanserlerin \%15,6's। ise hiperintens idi. T2A sekanslarda; PanNET'lerin \%61,1'i, adenokanserlerin \%62'si hiperintens, PanNET'lerin \%38, ${ }^{\prime} \mathrm{i}$, adenokanserlerin \%26,6'sı hipointens idi. Hem T1A hem de T2A sekanslarda izointens PanNET saptanmadı. Adenokanserlerde ise T1 ve T2 A sekanslarda izointens olan 5'er kitle vardı.

18 PanNET hastasının 6'sında (\%33,3), 45 adenokanser hastasının $15^{\prime}$ inde $(\% 33,3)$ karaciğer metastazı saptandı.

Adenokanser ve PanNET'lerde primer tümörlerden yapılan ölçümlerde ADC değerleri dağılımları istatistiksel olarak önemli bir farklılık göstermemektedir $(p=0.976)$ (Tablo 5). Aynı şekilde her iki gruba ait metastazlardan yapılan ADC ölçümlerinde de istatistiksel olarak anlamlı fark saptanmamıştır ( $p=0.140$ ) (Tablo 6).

PanNET: Pankreatik nöroendokrin tümör.

Tablo 5. Gruplar arasında primer kitlelerden ölçülen ADC değerlerine ilişkin istatistikler.

\begin{tabular}{lccccccc|}
\hline Grup & $\mathbf{n}$ & Ortalama & Standart Sapma & Medyan & Minimum & Maksimum \\
\hline PanNET & 18 & 1,03 & 0,39 & 1,00 & 0,37 & 2,00 \\
\hline Adenokanser & 45 & 1,01 & 0,22 & 0,99 & 0,45 & 1,60
\end{tabular}

ADC: Görünür difüzyon katsayısı, PanNET: Pankreatik nöroendokrin tümör.

Tablo 6. Gruplar arasında metastazlardan ölçülen ADC değerlerine ilişkin istatistikler.

\begin{tabular}{lccccccc}
\hline Grup & $\mathbf{n}$ & Ortalama & Standart Sapma & Medyan & Minimum & Maksimum \\
\hline PanNET & 25 & 0,77 & 0,17 & 0,74 & 0,42 & 1,10 \\
\hline Adenokanser & 67 & 0,86 & 0,27 & 0,83 & 0,39 & 1,70
\end{tabular}

ADC: Görünür difüzyon katsayısı, PanNET: Pankreatik nöroendokrin tümör.
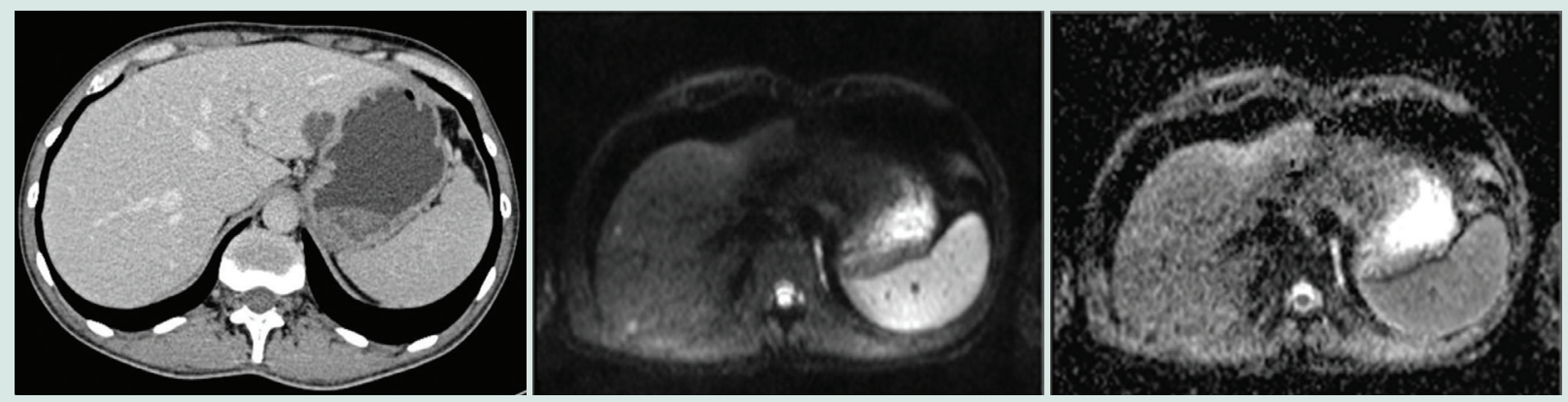

Resim 4 A,B,C. ÇKBT'de karaciğerde metastaz izlenmemektedir (A). Aynı hastanın DAG MR sekansında metastaz ile uyumlu hiperintens lezyon mevcuttur (B). ADC haritalamada aynı lezyon yine metastaz ile uyumlu olarak hipointens görünümdedir (C). 
Tablo 7. DAG MRG ve ÇKBT ile tespit edilen metastaz sayılarının kıyaslaması: Kırmızı ile belirtilen toplam 8 hastada DAG MR'da, ÇKBT'ye kıyasla daha fazla sayıda metastaz tespit etmiştir $(\% 38,10)$.

\begin{tabular}{|c|c|c|c|c|c|c|c|}
\hline & & BT & & & & & \\
\hline & & 0 & 1 & 2 & 3 & 4 & Multipl \\
\hline \multirow{6}{*}{ MR } & 0 & 0 & 0 & 0 & 0 & 0 & 0 \\
\hline & 1 & 3 & 1 & 0 & 0 & 0 & 0 \\
\hline & 2 & 0 & 1 & 0 & 0 & 0 & 0 \\
\hline & 3 & 0 & 0 & 0 & 1 & 0 & 0 \\
\hline & 4 & 0 & 0 & 1 & 0 & 0 & 0 \\
\hline & Multipl & 1 & 0 & 1 & 0 & 1 & 8 \\
\hline
\end{tabular}

DAG MRG: Difüzyon ağırlıkı manyetik rezonans görüntüleme. ÇKBT: Çok kesitli bilgisayarlı tomografi. BT: Bilgisayarlı tomografi MR: Manyetik rezonans.

Toplam 8 hastada DAG MRG'de, ÇKBT'ye kiyasla daha fazla sayıda metastaz tespit etmiştir $(\% 38,10)$. ÇKBT'de hiç metastaz tespit edilemeyen 3 hastada DAG MRG'de 1'er metastaz saptandı (Resim 4 A-C). DAG MRG'de multipl metastaz saptanan 2 hastanın birinde ÇKBT'de yalnız 4 metastaz, diğerinde yalnız 2 metastaz izlendi. 3 hastada DAG MR MRG'de tek metastaz saptanırken ÇKBT'de metastaz izlenmemiştir (Tablo 7).

\section{TARTIŞMA}

Pankreas kanseri şüphesi olan hastalarda özellikle ikter ile başvuran hastalarda tercih edilen ilk görüntüleme yöntemi USG'dir. Fakat pankreasın lokalizasyonu nedeniyle USG'nin pankreasın görüntülemesindeki yeri sınırıdır (1). Günümüzde hala pankreas kanseri tanısı için standart teknik kontrastlı BT tetkikidir. Pankreas kanseri hastalarında karaciğer metastazlarının tespit ve spesifiye edilmesinde kullanılan uluslarası bir kılavuz henüz yayınlanmamıştır. Ancak kontrastlı ÇKBT incelemelerde tespit edilen fakat spesifiye edilemeyen karaciğer kitlelerinde MRG'ye başvurulmaktadır $(8,9)$. Rutin post-kontrast venöz faz ÇKBT incelemelerde milimetrik boyutlu (küçük 20 mm) karaciğer metastazlarının bazıları ise izlenememektedir. Konvansiyonel MRG incelemelerinde de benzer sıkıntllar yaşanabilmektedir. Günümüzde DAG MRG inceleme konvansiyonel MRG sekanslarına ek sekans olarak aynı oturumda ve kısa sürede yapılabilmektedir. Üstelik bu incelemenin ilaç kullanımı ya da radyasyona maruz kalma gibi bir yan etkisi yoktur. Aynı zamanda fonksiyonel bir inceleme olan DAG'nin primer kitlenin ve metastazlarının değerlendirilmesindeki katkıııın geniş hasta serilerinde araştııılması gerekmektedir.

DAG su moleküllerinin hücre içi ve hücre dışı rastgele hareketlerinin değerlendirilmesi temeline dayanır (10). Dokunun selülaritesi ve membran yoğunluğu ile su moleküllerinin difüzyonu ters orantılıdır: Yüksek hücresel yoğunluğu olan biyolojik yapılar kısıtlı difüzyon bulgusu verecek ve yüksek $B$ değerlerinde alınan difüzyon sekanslarında hiperintens olarak izlenecektir $(11,12)$. Görünür difüzyon haritalarında ( $A D C$ birimi: $10^{-3} \mathrm{x} \mathrm{mm}^{2} / \mathrm{sn}$ ) ise bu alanlar hipointens olarak izlenir. B değeri difüzyon sekansının sensitivitesini belirleyen teknik bir parametredir (13). Yapılan birçok çalışmada kitlelerin malinite dereceleri arasında ADC değerlerinin anlamlı farklılık gösterdiği belirtilmiştir (14).

Bu çalışmada 63 pankreas kanseri tanılı hasta serimizde hastaların \%38,10'nunda; DAG MRG incelemedeki ADC haritalarında ÇKBT'den daha fazla karaciğer metastazı saptandı. Bu nedenle gereksiz cerrahi ve cerrahinin neden olduğu morbidite ve mortaliteden korunmak amacıyla pankreas kanseri tanılı hastalarda karaciğer metastazı saptanması ve dolayısıyla evrelemede DAG MRG'nin tarama amaçı gerçekleştirilmesi gerektiğini düşünmekteyiz.

Birçok kanser tipinde kitleler hipoksik ve hipovaskülerdir, fakat özellikle pankreatik adenokanser kitlelerinde bu özellik daha belirgindir (15-17). Pankreatik duktal adenokanser hastalarında tek tedavi yönteminin cerrahi olduğu düşünüldüğünde evreleme açısından hem primer kitlelerin hem de metastazlarının görüntüleme yöntemleriyle tanısının ne kadar önemli olduğu anlaşılmaktadır. Literatürde adenokanser hastalarında primer tümörün derecelendirilmesi ile ilgili çalışmalar vardır ancak sonuçlar tartışmalıdır. Genel olarak düşük dereceli tümörlerden düşük $A D C$ değerleri elde edildiği bildirilmiştir (18-20). Ancak buna hangi histolojik özelliğin esas olarak katkıda bulunduğu bilinmemektedir. Ayrıca pankreas tümörlerinin tedaviye yanıt değerlendirmesinde DAG bulgularını değerlendiren çalışmalar vardır ve tedavinin ADC değerini artırdığı bildirilmiştir (21).

Literatürde pankreas kanseri hastalarında hem primer kitlenin hem de karaciğer metastazlarının tanısında DAG'nin katkısını bildiren çalışmalar vardır, fakat tek başına yeterli 
olmadığı ve konvansiyonel dinamik MRG ile birlikte kullanılması gerektiği bildirilmiştir $(22,23)$. Holzapfel ve arkadaşları yaptıkları bir çalışmada karaciğer metastazlarında ÇKBT'nin \%53, DAG'ın ise \%86.7'lik bir duyarlılığa sahip olduğunu bildirmiştir (22). Chew ve O'Dwyer da yaptıkları başka bir çalışmada bu bilgiyi doğrulamışlardır (24). Bizim bulgularımı da bu literatür bilgilerini doğrulmaktadır. Hasta grubumuzdaki 10 adenokanser hastasında $(\% 22,22)$ tanı; hem T1A hem de T2A sekanslarda primer kitlenin izointens olması ve dinamik serilerde belirgin kontrastlanmaması nedeniyle DAG sekansları kullanılarak koyuldu. Bu hastalarda aynı zamanda konvansiyel MRG incelemelerde pankreas kanserinin sekonder bulguları vardı (çift kanal bulgusu, splenik ven obstrüksiyonu ve buna kollateral gelişimi v.b gibi). Çalışmamızda PanNET grubu hastalarda ise izointens lezyon saptanmadı.

PanNET'ler; mitoz sayısı ve mitotik indeksin oranına (\%KI67) göre iyi (G1), orta (G2) derecede farklılaşmış ve kötü (G3) diferansiye lezyonlar olarak sınıflandırılır [G1 (Ki67 <\%2,), G2 (Ki67 \%3-\%20) ve G3 (Ki67 >\% 20)] (25). Tedavi yöntemleri bu sınıflandırmaya göre; ameliyat ya da lokal ve sistemik tedavilere kadar değişiklik gösterir. Literatürde genel olarak G3 PanNET'lerin düşük ortalama ADC değerinde olma eğilimi bildirilmiştir (26-28). Bizim hasta grubumuzdaki PanNET'lerin 5'i G1, 8'i G2, 5'i G3 tümör idi ve hasta sayısının az olması nedeniyle bu açıdan anlamlı istatistiksel değerlendirme yapılamadı.

\section{KAYNAKLAR}

1. Amin MB, Edge $S$, Greene $F$, et al. AJCC Cancer Staging Manual. 8th ed. New York, NY: Springer; 20172.

2. Carpelan-Holmström M, Nordling S, Pukka E, et al. Does anyone survive pancreatic ductal carcinoma? A nationwide study re-evaluating the data of the Finnish Cancer Registry. Gut 2005;54:385-7.

3. Kazanjian KK, Hines OJ, Duffy JP, et al. Improved survival following pancreaticoduodenectomy to treat adenocarcinoma of the pancreas: the influence of operative blood loss. Arch Surg 2008;143:1166-71.

4. Tempero MA, Malafa MP, Al-Hawary M, et al. Pancreatic Adenocarcinoma. Version 2.2017, NCCN Clinical Practice Guidelines in Oncology. J Natl Compr Canc Netw 2017;15:1028-61.

5. Treadwell JR, Mitchell MD, Eatmon K, et al. Imaging Tests for the Diagnosis and Staging of Pancreatic Adenocarcinoma. Comparative Effectiveness Review No. 141. (Prepared by the ECRI Institute-Penn Medicine Evidence-based Practice Center under Contract No. 290-2012-00011-I.) AHRQ Publication No.14-EHC045-EF. Rockville, MD: Agency for Healthcare Research and Quality. September 2014. Available at: https://www.effectivehealthcare.ahrq.gov/ ehc/products/513/1973/cancer-pancreasexecutive-140923.pdf

6. Expert Panel on Gastrointestinal Imaging, Qayyum A, Tamm EP, Kamel IR, et al. ACR Appropriateness Criteria ${ }^{\circledR}$ Staging of Pancreatic Ductal Adenocarcinoma.J Am Coll Radiol 2017;14:S560-S569.

7. Ma C, Guo X, Liu L, et al. Effect of region of interest size on ADC measurements in pancreatic adenocarcinoma. Cancer Imaging 2017:17:13.
PanNET karaciğer metastazlarının çoğu durumda hipervasküler olduğu bilinmektedir. Bununla birlikte, bazı durumlarda izo veya hipovasküler olabilir (29). Bu nedenle PanNET hastalarında da tıpkı adenokanser hastalarında olduğu gibi doğru görüntüleme yöntemlerinin kullanılmasını ve DAG'ler gibi fonksiyonel görüntüleme yöntemlerinin konvansiyonel görüntülemeye eklenmesi gerektiğini düşünmekteyiz. Literatürde de PanNETlerin karaciğer metastazlarının belirlenmesinde DAG'nin yüksek sensitivite ve spesifiteye sahip olduğu bildirilmiştir $(30,31)$.

Çalışmada ÇKBT ve DAG MRG'de karaciğerde tespit ettiğimiz metastazların patolojik olarak tespit edilmemiş olması çalışmayı sınırlandırmaktadır. Bununla birlikte DAG ve kontrastlı MRG birlikte değerlendirilmiş ve metastaz tanısı konmuştur. Ayrıca operasyon ve tedavi sürecinde takip edilen bu hasta grubunda bulgularımız doğrulanmıştır.

Sonuç olarak; fonksiyonel görüntüleme yöntemlerinden biri olan DAG genel olarak pankreatik adenokanser ve PanNET'lerin tanısı ve karaciğer metastazlarının belirlenmesi açısından evrelemeyi iyileştirmektedir. Bu nedenle fonksiyonel radyolojik görüntülemeler MRG görüntüleme yöntemlerinin bir parçası olarak kullanılmalıdır ve pankreas kanseri hastalarında karaciğer metastazlarının belirlenmesinde ÇKBT ile sınırlı kalınmamalıdır. Böylece ÇKBT'de saptanmayan karaciğer metastazlarının DAG MRG ile tespit edilerek gereksiz operasyonlar, dolayısıyla da morbidite ve mortalite önlenmiş olur.

8. Poot DH, den Dekker AJ, Achten $\mathrm{E}$, et al. Optimal experimental design for diffusion kurtosis imaging. IEEE Trans Med Imaging 2010;29:819-29.

9. Yao X, Kuang T, Wu L, et al. Optimization of MR diffusion-weighted imaging acquisitions for pancreatic cancer at 3.0T. Magn Reson Imaging 2014;32:875-9.

10. Keogan MT, McDermott VG, Paulson EK, et al. Pancreatic malignancy: effect of dual-phase helical CT in tumor detection and vascular opacification. Radiology 1997;205:513-8.

11. Richter GM, Wunsch C, Schneider B, et al. Hydro-CT in detection and staging of pancreatic carcinoma [in German]. Radiologe 1998;38:279-86.

12. Nishiharu $T$, Yamashita $Y$, Abe $Y$, et al. Local extension of pancreatic carcinoma: assessment with thin-section helical CT versus with breath-hold fast MR imaging-ROC analysis. Radiology 1999;212:445-52.

13. Schima W, Függer $R$, Schober $E$, et al. Diagnosis and staging of pancreatic cancer: comparison of mangafodipir trisodium-enhanced MR imaging and contrast-enhanced helical hydro-CT. AJR Am J Roentgenol. 2002;179:717-24.

14. De Robertis R, Tinazzi Martini P, Demozzi E, et al. Prognostication and response assessment in liver and pancreatic tumors: The new imaging World J Gastroenterol 2015;21:6794-808.

15. Koong AC, Mehta VK, Le QT, et al. Pancreatic tumors show high levels of hypoxia. Int J Radiat Oncol Biol Phys 2000;48:919-22. 
16. Chang Q, Jurisica I, Do T, Hedley DW. Hypoxia predicts aggressive growth and spontaneous metastasis formation from orthotopically grown primary xenografts of human pancreatic cancer. Cancer Res 2011;71:3110-20.

17. Pizzi S, Porzionato A, Pasquali C, et al. Glucose transporter-1 expression and prognostic significance in pancreatic carcinogenesis. Histol Histopathol 2009;24:175-85.

18. Wang $Y$, Chen ZE, Nikolaidis $P$, et al. Diffusion-weighted magnetic resonance imaging of pancreatic adenocarcinomas:association with histopathology and tumor grade. J Magn Reson Imaging 2011;33:136-42.

19. Legrand L, Duchatelle $V$, Molinié $V$, et al. Pancreatic adenocarcinoma: MRI conspicuity and pathologic correlations. Abdom Imaging 2015;40:85-94.

20. Rosenkrantz AB, Matza BW, Sabach A, et al. Pancreatic cancer: lack of association between apparent diffusion coefficient values and adverse pathological features. Clin Radiol 2013;68:e191-7.

21. Niwa T, Ueno M, Ohkawa S, et al. Advanced pancreatic cancer: the use of the apparent diffusion coefficient to predict response to chemotherapy. Br J Radiol 2009;82:28-34.

22. Holzapfel K, Reiser-Erkan C, Fingerle AA, et al. Comparison of diffusion-weighted MR imaging and multidetector-row CT in the detection of liver metastases in patients operated for pancreatic cancer. Abdom Imaging 2011;36:179-84.

23. Miller FH, Hammond N, Siddiqi AJ, et al. Utility of diffusion-weighted $\mathrm{MRI}$ in distinguishing benign and malignant hepatic lesions. J Magn Reson Imaging 2010;32:138-47.

24. Chew C, O'Dwyer PJ. The value of liver magnetic resonance imaging in patients with findings of resectable pancreatic cancer on computed tomography. Singapore Med J. 2016;57:334-8.
25. Bosman FT, World Health Organization, International Agency for Research on Cancer. WHO classification of tumours of the digestive system. 4th ed. Lyon, France: IARC press, 2010.

26. Wang Y, Chen ZE, Yaghmai V, et al. Diffusion-weighted MR imaging inpancreatic endocrine tumors correlated with histopathologic characteristics. J Magn Reson Imaging 2011;33:1071-9.

27. Jang KM, Kim SH, Lee SJ, Choi D. The value of gadoxetic acidenhanced and diffusion-weighted MRI for prediction of grading of pancreatic neuroendocrine tumors. Acta Radiol 2014;55:140-8.

28. Hwang EJ, Lee JM, Yoon JH, et al. Intravoxel incoherent motion diffusion-weighted imaging of pancreatic neuroendocrine tumors: prediction of the histologic grade using pure diffusion coefficient and tumor size. Invest Radiol 2014;49:396-402.

29. Couvelard A, Deschamps L, Ravaud P, et al. Heterogeneity of tumor prognostic markers: a reproducibility study applied to liver metastases of pancreatic endocrine tumors. Mod Pathol 2009;22:27381.

30. d'Assignies G, Fina $P$, Bruno $O$, et alHigh sensitivity of diffusion-weighted MR imaging for the detection of liver metastases from neuroendocrine tumors: comparison with T2 weighted and dynamic gadolinium-enhanced MR imaging. Radiology 2013;268:390-9.

31. Singh N, Telles S. High frequency yoga breathing can increase alveolar dead space. Comment to: Gastroesophageal reflux disease and pulmonary function: a potential role of the dead space extension, Damir Bonacin, Damir Fabijanić, Mislav Radić, Željko Puljiz, Gorana Trgo, Andre Bratanić, Izet Hozo, Jadranka Tocilj, Med Sci Monit, 2012; 18(5): CR271-275. Med Sci Monit 2012; 18: LE5-L6; author reply LE5-L6. 